\title{
Docência na atualidade brasileira: rastreando controvérsias acerca do movimento Escola Sem Partido
}

\section{Teaching in the Brazilian Current Times: Tracking Controversies on the Unpolitical Schools Movement}

\author{
1 Julio Cesar de Almeida Nobre julio.nobre@foa.org.br \\ 1 Ivanete da Rosa Silva de Oliveira \\ 1 Marcos Paulo dos Anjos Corrêa de Carvalho \\ 1 Amanda Braga dos Santos \\ 1 Matheus Pires Andrade
}

1 Centro Universitário de Volta Redonda

\section{Resumo}

O movimento Escola sem Partido (ESP) assumiu visibilidade em 2014 com os projetos de lei (PL) que passaram a tramitar no Congresso Nacional e que são divulgados no site do ESP. Lideranças do ESP argumentam que o ensino deveria ser realizado exclusivamente com o objetivo da produção e difusão de conhecimento. Para tal, defendem a neutralidade nesse processo, argumentando pela abertura às diferentes abordagens investigativas e justificando seus posicionamentos com um suposto cenário onde um significativo número de docentes, dotados de concepções políticas, agiria com intenções de doutrinação discente. Parece que a atualidade da educação brasileira e, mais precisamente, os próprios contornos da docência, vivem momentos de intensa controvérsia que circulam em um cenário que mistura mediadores diversos. A fronteira da docência parece ser uma questão atual a ser respondida e definida por tal coletivo. Qual seria o papel do professor? 0 presente artigo, portanto, objetiva desenvolver uma cartografia descritiva da produção dos contornos daquilo que se entende por docência na atualidade brasileira. Busca-se evidenciar as redes heterogêneas de mediações que a produzem.

\section{Palavras-chave:}

Escola sem Partido. Docência. Teoria Ator-rede.

\begin{abstract}
The School Without Party (SWP) assumed visibility in 2014 with the projects of law (PL) that began to be processed in the National Congress and which are disclosed on the website of SWP. SWP leaders argue that teaching should be carried out exclusively with the objective of the production and diffusion of Knowledge. To this end, they advocate neutrality in this process, arguing for openness to the different investigative approaches and justifying their positions with an alleged scenario where a significant number of professors, endowed with political conceptions, would act with intentions of student indoctrination. It seems that the actuality of Brazilian education and, more precisely, the very contours of teaching, live moments of intense controversy that circulate in a scenario that mixes diverse mediators. The frontier of teaching seems to be a current question to be answered and defined by such a collective. What would be the teacher's role? This article, therefore, aims to develop a descriptive cartography of the production of the contours of what is meant by teaching in Brazil nowadays. It seeks to highlight the heterogeneous networks of mediations that produce it.
\end{abstract}

\section{Keywords:}

School Without Party. Teaching. Actor-Network theory.

\section{Como você deve citar?}

NOBRE, Julio Cesar de Almeida et al. Docência na atualidade brasileira: rastreando controvérsias acerca do movimento Escola Sem Partido. Cadernos UniFOA, Volta Redonda, n. 40, p. 57-72, agosto 2019. 


\title{
1 INTRODUÇÃO
}

O movimento Escola sem Partido (ESP) teve sua origem em um site veiculado em meados de 2004, porém passou a conquistar uma ampla visibilidade em 2014, tendo em vista os projetos de lei $(\mathrm{PL})$ que passaram a tramitar no Congresso Nacional em sintonia com temática do respectivo movimento (RIBEIRO, 2016). Segundo as lideranças do ESP, em nome da defesa da liberdade de expressão, o ensino deveria ser realizado com o objetivo da produção e consequente difusão de conhecimento. Para tal, defendem uma neutralidade, argumentando pela abertura às diferentes abordagens investigativas. Tais argumentos, segundo seus próprios autores, se justificam na medida em que existiria, no cenário da educação brasileira, um significativo número de docentes pertencentes a grupos políticos (ou dotados de concepções políticas) com intenções de doutrinação discente. Mais ainda. Afırmam que a: "(...) imensa maioria dos educadores e das autoridades, quando não promove ou apoia a doutrinação, ignora culposamente o problema ou se recusa a admiti-lo, por cumplicidade, conveniência ou covardia" (ESP, S/D).

O movimento coloca que a intenção primeira do respectivo site seria disponibilizar material que fortaleça o argumento de que há uma presença maciça de "doutrinadores" no país. Coloca-se, inclusive, como um canal para depoimentos nesse sentido.

\begin{abstract}
Se você sente que seus professores ou os professores dos seus filhos estão comprometidos com uma visão unilateral, preconceituosa ou tendenciosa das questões políticas e sociais; se percebe que outros enfoques são por eles desqualificados ou ridicularizados e que suas atitudes, em sala de aula, propiciam a formação uma atmosfera de intimidação incompatível com a busca do conhecimento; se observa que estão engajados na execução de um projeto de engenharia social, que supõe a implementação de uma nova escala de valores, envie-nos uma mensagem relatando sua experiência (ESP, S/D).
\end{abstract}

Ribeiro (2016) aponta que, a partir de 2014, diversas matérias abordando intimidações de docentes começaram a circular na mídia, até mesmo por meio judicial e utilizando um modelo de notificação disponibilizado no próprio site do ESP. A autora afirma que, em meados de 2015, aliados a grupos como o Movimento Brasil Livre (MBL) e o site Revoltados Online, o ESP trabalhou em defesa do impeachment de Dilma Rousseff, inclusive, apoiando o governo de Michel Temer e promovendo reunião do Ministro da Educação com o ator Alexandre Frota, uma das referências importantes do movimento.

O ESP, atualmente, divulga em seu site diversos Projetos de Lei em tramitação pelo país. Tais projetos demonstram a abrangência do respectivo movimento na medida em que circulam nas dimensões federal, estadual e municipal. Desse modo, parece que a atualidade da educação brasileira e, mais precisamente, os próprios contornos da docência, são foco de intensas controvérsias. Qual seria o papel do professor na educação brasileira? O que seria uma docência de qualidade? São perguntas que fazemos em uma realidade que parece instabilizar fortemente as fronteiras da docência na atualidade brasileira.

Vemos controvérsias que circulam em um cenário que mistura diversas dimensões, um tecido que articula política, docência, grande mídia, pesquisas, alunos, direito, dentre outros. Desse modo, entendemos que "o fato docência" parece ser uma questão atual a ser respondida em sua imbricação com mediadores diversos. 0 presente artigo, portanto, objetiva desenvolver uma cartografia descritiva da produção das fronteiras daquilo que se entende por docência na atualidade brasileira. Busca-se evidenciar as redes heterogêneas de mediações que produzem tais fronteiras. 
Julio Cesar de Almeida Nobre I Ivanete da Rosa Silva de Oliveira Marcos Paulo dos Anjos Corrêa de Carvalho / Amanda Braga dos Santos I Matheus Pires Andrade

\section{A DOCÊNCIA NA ATUALIDADE BRASILEIRA: A TEMÁTICA DA ESCOLA SEM PARTIDO}

Quando nos aproximamos das fronteiras do ofício de professor, nos deparamos com autores que remontam um passado bastante antigo. Segundo Nóvoa (1991), a gênese da profissão docente é anterior à estatização da escola, pois, desde o século XVI, já existiam vários grupos de leigos e religiosos que se dedicavam a atividade docente.

A prática da educação é muito anterior ao pensamento pedagógico. 0 pensamento pedagógico surge com a reflexão sobre a prática da educação, como necessidade de sistematizá-la e organizá-la em função de determinados fins e objetivos (GADOTTI, 2006, p. 21).

A profissão docente foi por muito tempo um ofício visto como vocação, nos moldes sacerdotais ou dom, por isso, nem mesmo o status de profissão era considerado. Este só foi surgir na Idade Média fortemente influenciado pela Igreja que valorizava os professores como os porta-vozes de preceitos morais (SÁ, 2016). Nóvoa (1995) aponta que, no Brasil, com a chegada dos portugueses, o ensino se manifestou a priori como ferramenta de dominação com viés religioso e que essa configuração se manteve até metade do século XVIII, quando a educação passou a ser concebida como emanando do Estado e para o Estado, dando início à normatização e organização do exercício da profissão docente.

O processo de estatização do ensino consiste, sobretudo, na substituição de um corpo de professores religiosos (ou o controle da Igreja) por um corpo de professores laicos (ou sob o controle do Estado), sem que, no entanto, tenha havido mudanças significativas nas motivações, nas normas e nos valores originais da profissão docente: o modelo do professor continua muito próximo do padre (NÓVOA, 1995, p.15).

Após a Revolução industrial, o papel da escola é ampliado, pois a instrução básica é entendida como necessária para uma grande camada da população que compreendia os operários das fábricas. Com isso, para fomentar as políticas desenvolvimentistas, a demanda por professores aumentou, promovendo uma mudança geral de perspectiva sobre a educação, que passava a ser vista como essencial para o desenvolvimento social. Desde então, ocorreram drásticas mudanças no que tange à educação brasileira (SÁ, 2016).

No momento recente, a potencialização da comunicação trouxe um aumento significativo nas interações e visibilidade à diversidade cultural, produzindo conhecimentos mais disponíveis. Nesse cenário, o professor tem seu papel relativizado, por não mais centralizar o saber, deixando de ser o protagonista e passando a ser um mediador do processo ensino-aprendizagem. Assim, novas abordagens pedagógicas se manifestam. Em meio a (re) desenhos da educação, a docência vem sendo produzida como uma matéria instável, na qual não há uma reciprocidade de consentimentos. Desse modo, não é surpreendente que elementos hodiernos tragam ainda mais controvérsias para suas fronteiras, fazendo com que esta se transforme e ao mesmo tempo provoque transformações.

Voltando nosso olhar para a realidade brasileira, na atualidade, parece ganhar potência a percepção de que existiria uma doutrinação ideológica e político-partidária dentro das salas de aula. 0 movimento ESP pode ser considerado um dos fortes difusores de tal concepção na realidade brasileira. Tal grupo argumenta que, em função do amplo desenvolvimento da tecnologia e dos meios de comunicação, tais práticas acabaram por se tornar muito mais visíveis, transcendendo a sala de aula e se colocando fora do princípio da neutralidade do Estado, que deveria garantir o livre arbítrio dos cidadãos. Agindo desse modo, na opinião dos autores do movimento, o docente acabaria por favorecer a uma perspectiva política única, articulando o ato de ensinar com seu interesse particular, produzindo lacunas na aprendizagem. A docência considerada como prática doutrinadora promoveria um quadro de alienação do estudante e os professores não ensinariam tudo aquilo que o aluno deveria aprender, desequilibrando o ensino devido a um viés político. 
Com o objetivo de coibir tal suposto abuso da liberdade de ensinar que se desenvolveria veladamente nas salas de aula, tendo como vítimas indivíduos vulneráveis em processo de aprendizado, o ESP aponta suas baterias para possíveis doutrinações políticas, morais e religiosas. Defendem a veiculação de cartazes em salas de aula, explicitando os deveres inerentes ao ofício da docência, salientam que os professores possuem um forte vínculo com os discentes e que estes passam a maior parte das horas do dia dentro das respectivas salas de aula. Sendo assim, os componentes do ESP costumam explicitar que a docência deve ser exercida de forma neutra. A docência configurada como prática de neutralidade pode ser entendida como aquela que apresenta lados diversos de uma mesma temática, possibilitando que o aluno forme sua própria opinião acercado conteúdo. Salienta-se que os defensores do respectivo movimento afirmam não terem a proposta de impedir que um professor venha a abordar temas políticos, visto que isso impediria o ensino de disciplinas, como História ou Geografia. São enfáticos ao se posicionarem pela abordagem de diversos ângulos, a fim de evitar o que chamam de exagero, com o objetivo de obter a adesão dos alunos à determinada corrente ideológica, política ou partidária. Vemos isso, por exemplo, no item 4 do Cartaz, com os Deveres do Professor:

(...) ao tratar de questões políticas, socioculturais e econômicas, o professor apresentará aos alunos, de forma justa, isto é, com a mesma profundidade e seriedade as principais versões, teorias, opiniões e perspectivas concorrentes a respeito (ESP, s/d).

Outra tese defendida pelo ESP é a compreensão de que os pais têm o direito que seus filhos recebam a educação religiosa e moral de acordo com suas próprias convicções. Para respeitar esse direito, o movimento afirma que o professor deve apresentar conteúdos e realizar atividades de cunho religioso ou moral de forma neutra, a fim de evitar conflitos com a convicção dos pais ou responsáveis pelos estudantes. Inclui-se nesse argumento as questões relacionadas à moral sexual. Salientam que a violação a esse dever de abstenção expõe o professor ao risco de responder, pessoalmente, nos termos da lei civil, pelos danos que vier a causar ao estudante ou sua família ${ }^{2}$.

A ideia seria a produção de cartazes implantados nas salas de aula, bem como a ênfase de que os professores que não cumprissem os deveres que lá estariam poderiam sofrer sanções civil (reparação dos danos eventualmente causados aos alunos), administrativa (punição disciplinar) e penal, com condenação de até seis meses de detenção, perda do cargo e inabilitação para o exercício de qualquer outra função pública por até três anos (ESP, s/d).

Essa tessitura produzida pelo ESP potencializa até mesmo uma proposta de lei federal que objetiva normatizar o ensino em todos os níveis, no sentido de evitar doutrinas ideológicas, especificando os limites de atuação do professor para que ele não promova suas crenças ou visões dentro de uma sala de aula, estabilizando a concepção de docência.

Tal cenário parece se caracterizar por posições bastante entrincheiradas. Em obra publicada em 2016,"A ideologia do movimento escola sem partido: 20 autores desmontam o discurso", vemos argumentos que objetivam demonstrar que tais ideais, colocadas de maneira tão teoricamente convincentes, teriam o real intuito de retirar o direito de uma escola livre, democrática e plural. Estaria negando a possibilidade de a escola aceitar e abranger toda e qualquer pessoa, respeitando suas características individuais, sejam elas de religião, política, etnia, gênero ou qualquer outra manifestação. Enfim, vemos significativos autores que argumentam e se colocam como diametralmente opostos ao ESP por considerarem limitado ao ponto de não garantir o desenvolvimento da autonomia discente.

2 As escolas particulares cujas práticas educativas sejam orientadas por concepções, princípios e valores morais, religiosos ou ideológicos, o movimento reconhece expressamente o direito de veicular conteúdos e promover atividades, desde que previamente autorizadas pelos pais ou responsáveis pelos estudantes. 
Roberto Catelli Jr. (2016), um dos autores da obra supracitada, argumenta que o ESP difunde uma falsa ideia de que o referido programa tem como base de seu desenvolvimento a defesa de certa dose de imparcialidade na educação, deixando no ar uma pergunta importante: como desenvolver um indivíduo em meio a relações onde o diálogo não se faz presente? Na verdade, estaríamos por ver uma "cortina de fumaça" que ocultaria a intenção de manter o aluno passivo e, consequentemente, coadjuvante no desenvolvimento social. $\mathrm{O}$ autor aponta que a necessidade de um aluno é de que haja informação e diálogo, no sentido de fazer com que eles possam governar-se a ponto de construir opiniões e discutir entre si. "Não existe conhecimento histórico, sociológico, filosófico ou de qualquer área de conhecimento que seja neutro ou imparcial"(CATELLI JR, 2016, p. 86).

Diversos são os argumentos que se opõem ao ESP por entender que ele criminaliza debates em pleno século XXI em prol de certo silenciamento, como aqueles articulados à homofobia, ao preconceito racial, aos direitos humanos, dentre outros. Afirmam que tais posicionamentos acabam por estimular a manifestação e o crescimento de sentimentos hostis e intolerantes que se contrapõem ao reconhecimento da diversidade, sob a forma de ameaça a um professor, configurando a docência como uma prática acuada e silenciada.

Frei Betto (2016) afirma ser impossível compreender e acatar um movimento que intenciona calar a diversidade de opiniões e visões de mundo não paralelas em favor de uma ideia restritiva que proíbe a evolução de políticas públicas educacionais referentes a gênero, sexualidade e formação cidadã, sendo que nada somaria na vida de um indivíduo. Mais ainda, argumenta que reforçaria o preconceito e uma atitude antidemocrática.

Na verdade, muitos "sem partido" são partidários de ensinar que nascemos todos de Adão e Eva; homossexualidade é doença e pecado (e tem cura!); identidades de gênero é teoria promíscua; e o capitalismo é o melhor dos mundos (BETTO, 2016: p. 66).

Eduardo Girotto (2016) entende que uma ESP teria referências tecnicistas, insistindo em tentar dar poder a um ensino contrário às experiências de sucesso em outros países que têm por base a interação, onde os professores são a fonte de estímulo a uma educação pautada na consciência crítica e no respeito à diversidade de posicionamentos.

(...)é com esta perspectiva que gostaríamos de dialogar, argumentando que é preciso compreender o lugar do Escola Sem Partido em um contexto mais amplo de construção de uma escola do pensamento único, pautada nos pressupostos de uma certa racionalidade técnica e gerencial, que tem ganhado força e destaque nas últimas décadas no país, estando presente em inúmeras políticas educacionais postas em prática(...) (GIROTTO, 2016, p. 70).

Tais contrapontos, portanto, argumentam pela necessidade da não permissão da disseminação da ESP, com a finalidade de não estancar o que entendem por conquistas democráticas e igualitárias da Constituição e impedir que se reforcem preconceitos a partir de seus discursos intimidadores. Enfatizam que ir contra o ESP não se trata apenas de defender os direitos do professor e sua liberdade de cátedra, mas também de colocar a escola como um espaço democrático, de liberdade e não de indiferença. Temos discursos que demonstram que, quando um docente leva os próprios sentimentos para a sala de aula e faz com que alunos reflitam sobre o que estão vendo e vivendo, ele não deve ser entendido como tentando influenciá-lo a tomar um partido. A neutralidade, sim, seria uma forma de alienação do cotidiano da vida. Não ter partido parece significar ter acesso à diversidade de pensar, mas não é bem assim quando um professor pode apenas reproduzir conteúdo.

Disso, portanto, se poderia supor que os professores da escola pública, como funcionários de um Estado "neutro", ensinariam a seus alunos sobre diferentes formas religiosas e variadas correntes de pensamento político, todos apresentados com uma mesma ênfase (VASCONCELOS, 2016, p. 80). 


\section{A TEORIA ATOR-REDE: UM MÉTODO MINIMALISTA}

Em nossa atual conjuntura, observa-se inserido o elemento da polarização nos principais cenários. Diversas percepções exteriorizadas, quando colocadas em linha, parecem demonstrar uma concepção predominante, na qual se entende a realidade a partir da subjetividade de seu contexto e que, por conseguinte, trazem análises apoiadas nos interesses que contornam determinado fato, para assim poder explicá-lo. Todavia, a presente análise utiliza como referencial teórico-metodológico, uma ótica que segue o caminho inverso, trazendo para si possibilidades de análise que fogem de uma perspectiva de unidade, dando ênfase a um olhar dinâmico sobre os processos e associações presentes no social.

A teoria Ator-Rede, articulada com pesquisadores como Bruno Latour, John Law entre outros, provoca uma reflexão acerca da estrutura de produção e percepção dos fatos sociais. Quando negam uma hermenêutica purista e promovem a concepção das redes, dos fluxos, admitem que não basta apenas observar as disputas de interesses para compreender a produção dos fatos. Faz-se necessário também conceber as diversas associações existentes de humanos e não humanos dentro de uma lógica sistemática. Dessa forma, observa-se que os artefatos técnicos possuem uma grande relevância na matéria, sendo tratados de modo simétrico aos humanos ao observarmos o fator social (LATOUR, 2008).

Com isso, é visível uma conotação de vínculo, acoplamento e até mesmo de nexo entre os elementos dissemelhantes e com propriedades distintas inseridos em uma mesma rede. Nessa senda, a transmutação dos fluidos em circuito é possível através da mediação, promovendo uma abertura para um caráter dinâmico e volátil caracterizado como a forma predominante de operação dentro de uma rede com objetos diversos e de disciplinas distintas. Dessa forma, o entendimento dos "desdobramentos sociais" observa o sujeito não apenas como um ator, mas sim como actante de um processo de fluxos na conjuntura em que o mesmo atua com seus artefatos.

O segredo é definir o ator com base naquilo que ele faz - seus desempenhos (...). Uma vez que, em inglês, a palavra actor (ator) se limita a humanos, utilizamos muitas vezes actant (atuante), termo tomado à semiótica, para incluir não-humanos na definição (LATOUR, 2001, p. 346).

A afluência dos objetos sociais, assim como as novas conceituações e produções, observadas sob essas perspectivas, não se configuram mais como matérias independentes. Denotam, sim, outro caráter, isto é, o de serem produções e produtoras simultaneamente, fugindo a ambivalência moderna de qualificá-las como imanentes e transcendentes.

Salienta-se que, no momento hodierno, é possível e evidente observar controvérsias nas mais diversas temáticas. Desse modo, ao relembrarmos que os objetos sujeitos de análise não são estáticos e, muito menos, com fins em si mesmos, são entendidos como híbridos interfronteiras, em que cada uma das diversas argumentações e resistências é resultado de uma produção complexa de humanos e não humanos. Tal produção, portanto, é passível de ser rastreada em seu processo de fabricação. Ademais, quando não há controvérsias demasiadas em determinada matéria, havendo, portanto, uma reciprocidade de consentimentos e, por conseguinte, uma maior estabilização da realidade, temos a denominada caixa-preta (LATOUR, 2000). Tratando-se de caixas-pretas, não podemos cair no erro de pensar que elas transcendem o caráter volátil e constante das produções, pelo contrário, através das mediações $^{3}$ é concebível desestabilizar aquelas.

3 Mediação é o diálogo ou ação entre diversos atores em que não há causalidade facilmente identificável. Ela se dá de acordo com os modos, ou seja, é uma ação a partir de maneira pela qual se dá o processamento, a troca, o consumo e a produção infocomunicacional local entre os atores(LEMOS, 2010: 11). 
Julio Cesar de Almeida Nobre I Ivanete da Rosa Silva de Oliveira Marcos Paulo dos Anjos Corrêa de Carvalho / Amanda Braga dos Santos I Matheus Pires Andrade

Essa possibilidade factual não apenas demonstra uma sofisticada abordagem teórica de Latour, mas também o âmago social transcrito conceptualmente. Revela o mundo humano e artificial, não como objetos autônomos, mas em constante comunicação, ainda que essas relações não sejam visíveis sob um primeiro olhar. Mais ainda, aponta para uma sociedade complexa de produtos simultaneamente produtores, nos quais a sociedade não se exibe e avança apenas com a pugnação de interesses diversos, mas sim com a qualidade de uma conflagração coletiva na produção de novos objetos. Tal possibilidade de abertura das caixas-pretas são entendidas pelos teóricos de tal referencial como caixas-cinzas.

O termo caixa-preta (...) é utilizado na sociologia das ciências para falar de um fato ou de um artefato técnico bem estabelecido. Significa que ele não é mais objeto de controvérsia, de interrogação nem de dúvidas, mas que é tido como um dado (...). Quando uma técnica ainda não está completamente estabelecida como caixa-preta, falamos de caixa-cinza (VINCK, 1995, p.176).

Essas caixas-cinza se difundem em redes, gerando novas produções e podendo se estabilizar. Contudo, Latour (2000) estabelece parâmetros para se observar as redes, demonstrando que a inobservância de tais pressupostos pode acarretar em uma desvirtuação temática e uma impossibilidade de seguir os rastros do processo em pauta. Uma regra de importância extrema se configura como uma atenção que o pesquisador deve dar para o fato de que a estabilização da natureza ou da sociedade é sempre uma consequência da resolução de controvérsias, o que não se confunde com a resolução de suas causas. As controvérsias se apresentam, portanto, como fator significativo para o rastreamento das redes, pois é no decurso das associações e eventuais controvérsias que o elemento social se torna conspícuo, dado que, após a resolução daquela, apesar de continuar havendo um esforço no sentido de preservar os novos objetos sociais criados, o mesmo é ocultado pelo fechamento da caixa-preta. Dessa forma, para inquirir um produto social, se requer uma prática de pesquisa no sentido de trazer luz aos objetos invisibilizados, ou seja, o "foco está na cozinha dos fatos, nas mediações e nas práticas" (LATOUR, 2000, p.83-84).

Nossa intenção no presente artigo, portanto, é realizar um rastreamento das controvérsias acerca daquilo que entendemos sobre o artefato docência. Entendemos que o referencial exposto trará lucidez para a compreensão e análise das associações diversas a produzirem coletivamente as fronteiras híbridas da docência em meio às controvérsias do movimento ESP. A proposta seria seguir pistas e rastros em meio a pontos e contrapontos, aliados e resistências de diversas ordens que, de mediação em mediação, delineiam uma docência em ação. Escolhemos como porta de entrada para a respectiva controvérsia, além da mídia acadêmica, a grande mídia, por entendermos que, na nossa atualidade altamente midiática, tais recursos possuem um significativo poder de reverberação social.

\section{RASTREANDO CONTROVÉRSIAS}

Em uma atualidade de forte ampliação dos processos comunicacionais e grande turbulência no cenário pedagógico, o Programa ESP se insere como mais um elemento instabilizador da docência no cenário nacional. Pode-se observar tal instabilidade ganhar espaço nas mídias brasileiras com muita frequência. Ao nos aproximarmos delas, vemos o Jornal diário El País traduzir o quadro atual como uma 'guerra ideológica' e ainda o qualificar como perigoso:"(...) a polarização ideológica que atingiu o país nos últimos anos tem levado a educação para o centro de uma batalha que começa a ter contornos perigosos" (BEDINELLI, 2016).

Segundo o Jornal, o movimento ESP “(...) foi criado a partir da indignação de um pai com um professor". Esse cenário se montou quando a filha do advogado Miguel Nagib relata a ele que, em uma das aulas, o professor havia feito uma comparação entre Che Guevara e São Francisco de Assis, a fim de ilustrar personalidades que abriram mão de tudo por uma ideologia. 0 advogado leu a situação como 
uma tentativa de o professor doutrinar ideologicamente seus alunos e, em seguida, tomou algumas medidas: fez uma carta aberta para o professor expressando sua indignação, porém, como não houve anuência e interesse dos demais pais, Nagib resolveu criar uma associação com a finalidade de «(...) lutar contra o abuso do qual as crianças estão sendo vítimas" (BEDINELLI, 2016).

A ideia de Nagib parece ter desabrochado e ganhado ressonância ao passo que os ânimos sociais se enervaram e a docência parece, gradativamente, ir se articulando com uma concepção de doutrinação de alunos. No momento presente, há diversos projetos de lei em tramitação em câmaras municipais, assembleias legislativas e no próprio Congresso Nacional que têm a pretensão de disciplinar como deve ser a postura do professor em sala de aula, e vai além, tratam acerca dos materiais didáticos e, até mesmo, sobre a interferência direta dos pais nos conteúdos escolares que seus filhos recebem.

Também em matéria da Revista Exame (2016), "o advogado Miguel Nagib, que idealizou o texto do programa "Escola Sem Partido" em 2004, vê o projeto como uma iniciativa necessária para assegurar o respeito à Constituição Federal no segredo das salas de aula" (RIBEIRO, 2016).

Nesse trecho, Nagib parece traduzir a docência na atualidade brasileira como uma espécie de "oportunismo" diante dos estudantes, visto que traduz tal situação como povoada por docentes que se aproveitam da audiência dos alunos em sala para promover seus próprios interesses. Desse modo, o professor poderia estar prejudicando os alunos, mostrando somente um lado e ocultando o outro, incitando-os a participar de manifestações, atos públicos e passeatas. 0 advogado parece traduzir tal docência na atualidade como um fator a alienar os alunos de si, de seus potenciais reais. Nagib continua:

(...) ao tratar de questões políticas, socioculturais e econômicas, apresentar aos alunos, de forma justa - isto é, com a mesma profundidade e seriedade - as principais versões, teorias, opiniões e perspectivas concorrentes a respeito da matéria (RIBEIRO, 2016).

Para ele, portanto, o projeto parece ter o objetivo de defender o aluno diante de uma prática docente unilateral e "oportunista" que impõe a sua própria opinião em sala de aula.Na mesma matéria da Revista Exame, encontramos também argumentos do senador Magno Malta, idealizador do projeto de lei 193/2016 no Senado, que objetiva incluir nas Diretrizes e Bases da Educação Nacional, o Programa ESP. "(...) a escola é o lugar que abre janela para o conhecimento. Em sua opinião, porém, as escolas não estão desempenhando esse papel desde que o PT assumiu a presidência da República" (RIBEIRO, 2016).

O Senador trata a docência como algo direcionado a determinado ponto de vista vindo da parte do educador, no qual ele deveria ensinar de forma neutra. Malta argumenta que, desde 2002, época em que o PT (Partido dos Trabalhadores) assumiu a Presidência do Brasil, as instituições de ensino têm feito uma pregação ideológica, partidária, política e religiosa. Ele afirma que nenhum aluno merece estar à mercê do pensamento de seus professores, pois precisa ter o conhecimento de forma ampla para a construção de sua própria opinião. Vemos, portanto, a tradução de uma docência engajada politicamente em detrimento de um verdadeiro papel a ser desempenhado, de abrir janelas para um conhecimento puro e despolitizado. Conhecimento e política parecem produzidos como estanques. Em apoio ao programa ESP, o Senador indica que já ouviu relatos de doutrinação em salas de aula. Critica tal prática, traduzindo tais espaços como locais de aprendizado (RIBEIRO, 2016).

Até julho de 2016, já eram nove estados brasileiros, além do Distrito Federal, que possuíam ao menos um projeto com um teor semelhante aos do Movimento (MORENO; TENENTE; FAJARDO, 2016). Contudo, a primeira normatização da matéria foi em Alagoas, abril de 2016, que instituiu em lei o programa "Escola Livre", prevendo a vedação no âmbito do ensino regular estadual, a prática de "doutrinação política e ideológica", bem como quaisquer outras condutas por parte do corpo docente ou da 
Julio Cesar de Almeida Nobre I Ivanete da Rosa Silva de Oliveira Marcos Paulo dos Anjos Corrêa de Carvalho / Amanda Braga dos Santos I Matheus Pires Andrade

administração escolar que imponham ou induzam os alunos a opiniões político-partidárias, religiosa ou filosófica ${ }^{4}$.

No ano seguinte, a Confederação Nacional dos Trabalhadores em Estabelecimento de Ensino entrou com uma ação direta de inconstitucionalidade contra a respectiva lei. O Ministro Barroso atendeu ao pedido de liminar e disse, em sua decisão sob a ótica constitucional, que é atribuição exclusiva da união legislar acerca da organização de ensino. Afırmou ainda que a constituição assegura

(...) uma educação emancipadora, que habilite a pessoa para os mais diversos âmbitos da vida, como ser humano, como cidadão, como profissional. Com tal propósito, define as diretrizes que devem ser observadas pelo ensino, a fim de que tal objetivo seja alcançado, dentre elas a mencionada liberdade de aprender e de ensinar; o pluralismo de ideias e de concepções pedagógicas; a valorização dos profissionais da educação escolar (NOTíCIAS STF, 2017).

O ESP segue enfrentando significativas resistências. Em artigo intitulado "Lei da mordaça em São Lourenço do Sul é um atentado à escola pública"(SCHURER, 2018), temos uma crítica a aprovação do respectivo Projeto, na cidade situada no RS. A docente autora do artigo expõe que tal proposta, intitulada por ela como "discurso fantasioso" que busca ensinar o docente a ensinar, inseriu a intolerância no trabalho do professor, além de silenciamento. Ela, enquanto professora, argumenta por uma escola onde o docente tenha seu trabalho reconhecido, valorizando a cidadania, reforçando a igualdade, em detrimento da militarização e repressão. A professora traduz o Projeto como um instrumento que age no sentido de retirar a autonomia do docente e censurar a visão crítica do aluno. Embasa seus argumentos na necessidade de pluralidade e livre expressão dentro das escolas.

Em reportagem do EI País (TRAVINCAS, 2018), uma professora de Direito afirma que a liberdade de ensinar está ligada à possibilidade do professor se expor e escolher suas metodologias de ensino. Defende a importância das opiniões diversificadas no sentido de romper com os paradigmas da pessoalidade do aluno para que ele possa refletir sobre suas posições na sociedade. Argumenta ainda que existe distinção entre ensinar e doutrinar, pois quem doutrina não dá opção de contestamento; já aquele que ensina, dá ao aluno a opção de questionamento e discussão acerca do assunto. Tendo tais posições como referência, a professora traduz o ESP como «uma premissa equivocada» e um «modelo de educação absolutamente retrógrado", que acabaria por trazer a possibilidade de problemas para o professor, mesmo que ele apenas reproduzisse o conteúdo, visto que qualquer forma de ensino sempre imprime alguma subjetividade.

Sem uma distinção clara sobre qual é a configuração do ESP, vemos que ele assumiu diversas formas e discursos distintos, influenciando nos diversos delineamentos de docência. Porém, isso parece não ter impedido seu avanço, com a reprodução de afirmativas que já refletem um senso comum ressonante em nossa conjuntura atual. Por mais que o conceito do ESP agora se mostre mais difuso, isso não impediu que diversos setores sociais se posicionassem de forma contrária a ele. 0 próprio governo vigente demonstrou uma posição acerca do projeto. Afirmou o ministro da Educação, Mendonça Filho, em entrevista ao G1 que, "(...) conceitualmente, tenho a posição de que não será por meio de uma legislação assim que se resolve a questão"(MORENO, 2016).

Mesmo com a posição contrária do ministro, a positivação em lei oriunda dos processos articulados ao movimento ESP parece demonstrar que o andamento da matéria tem como meta a conquista de um novo regramento realmente. Tal conclusão parece provocar outros atores importantes. Clovis Gruner,

4 Vale ressaltar que Miguel Nagib, idealizador do programa, afirma que seu projeto "não corresponde exatamente ao que foi aprovado em Alagoas". Temos controvérsias mesmo entre os defensores do Movimento. O advogado salienta que seu programa consiste apenas em fixar, nas escolas, os "deveres do professor" - que, segundo ele, já existem no texto constitucional e serviriam para conscientização e proteção dos alunos. 
Docência na atualidade brasileira:

rastreando controvérsias acerca do movimento Escola Sem Partido

professor adjunto do Departamento de História da Universidade Federal do Paraná, afirma que, caso a lei saia do papel, sua constituição deverá ser amplamente discutida por um grupo de especialistas.

Eu não defendo que o professor possa dizer o que ele quiser em sala de aula, não é isso. Mas a escola não pode ser alheia à diversidade, inclusive geográfica e social. E se os projetos virarem lei, os conteúdos seriam ministrados sem ser contextualizados. (...) outro risco é o de criar uma geração de alunos dedo duros, de professores que eventualmente escapem" (MORENO; TENENTE; FAJARDO, 2016).

Parecendo estar em sintonia com tais argumentos, a jurista Raiana Erica Braun (2016), ao discutir sobre a constitucionalidade do projeto, afirma que "o art. 206, inciso II da Constituição Federal (1988) é claro ao ordenar que o ensino escolar deve ser ministrado com base nos princípios da liberdade de aprender, de ensinar, pesquisar e divulgar o pensamento, a arte e o saber"(BRAUN, 2016). Registra ainda que "seguidamente o inciso II do mesmo artigo expõe o direito ao pluralismo de ideias e de concepções pedagógicas" (BRAUN, 2016), se refere ao ESP argumentando que

(...) tudo aquilo que diverge deste sentido é visto como afronta ao estado democrático de direito e à liberdade do exercício do profissional de pedagogia, o colocando em constante vigilância e o impedindo de práticas pedagógicas pluralísticas (BRAUN, 2016).

Nesse contexto conturbado, o Senado Federal abriu consulta pública sobre o PL do Senado n¹93, de 2016, que tinha como ementa a inclusão do Programa ESP entre as diretrizes e bases da educação. Em 2017, a votação expressava uma opinião pública favorável ao projeto, mesmo que por uma margem pequena (cerca de 30.000 votos favoráveis em relação a28.000 contrários). Porém, salienta-se que, em nova apuração realizada em 18/09/2018, o cenário demonstra que a opinião pública agora se posiciona contra o projeto (com 210.819 votos contrários em relação a 199.873 favoráveis), sendo votado e rejeitado em 13/12/18.

Apesar de tal cenário, o projeto vem acumulando vitórias. O Jornal Folha de São Paulo relata que "a comissão especial destinada a analisar o projeto de lei conhecido como escola sem partido, capitaneado pela bancada evangélica, apresentou relatório favorável à proposta" (BOLDRINI, 2018). 0 jornal ainda aponta que o texto do Projeto proíbe o uso da palavra "gênero" e da expressão "orientação sexual" em sala de aula (no voto, o relator criticou o que afirma ser a propagação de uma "ideologia de gênero").

É importante salientar que tal controvérsia não vem repercutindo apenas em território nacional. Segundo o jornal Estadão, relatores da Organização das Nações Unidas (ONU) classificam o ESP como censura, traduzindo o respectivo Programa como"(...) restrição indevida ao direito de liberdade de expressão de alunos e professores no Brasil"(TOLEDO; CHADE, 2017).Em contrapartida, o idealizador do movimento, Miguel Nagib, discorda de tais posicionamentos que traduzem o Projeto como algo a se chocar com os Direitos Humanos, quando afirma que parte do texto foi inspirada, exatamente, na Convenção Interamericana de Direitos Humanos que diz, em um dos seus artigos, que "os pais, e quando for o caso os tutores, têm direito a que seus filhos recebam a educação religiosa e moral que esteja em acordo com suas próprias convicções" (TOLEDO; CHADE, 2017).

Considerando o relato até então desenvolvido, percebe-se que múltiplos mediadores e actantes produziram a docência na atualidade imbricada com o movimento ESP. Contudo, durante a realização do presente artigo, as eleições presidenciais se manifestaram como protagonista de uma rede complexa, potencializando os debates, dando ressonância e configurando o cenário de forma mais instável e suscitando ainda mais controvérsias. O presidente eleito, Jair Bolsonaro, publicou em sua rede social particular (2/10/2018),antes mesmo de sua vitória ser confirmada nas urnas que "a questão ideológica é tão, ou mais grave, que a corrupção no Brasil. São dois males a ser combatido (sic). 0 desaparelhamento do Estado, e o fim das indicações políticas, é o remédio que temos para salvar o Brasil"(G1, 2018). Tal declaração parece estar consoante com um sentimento de aversão a posicionamentos políticos "de 
Julio Cesar de Almeida Nobre I Ivanete da Rosa Silva de Oliveira Marcos Paulo dos Anjos Corrêa de Carvalho I Amanda Braga dos Santos / Matheus Pires Andrade

esquerda" aflorado nos ânimos populares nos últimos anos. Além do mais, esse sentimento se revela como fundamento para uma lógica de "neutralidade" multifacetária. Essa linha de pensamento vem se articulando para legitimar os mais diversos programas. A exemplo, visualizamos tal contexto na manifestação do ex-senador Magno Malta, idealizador do Projeto de Lei n 193/2016, aliado e anunciado como futuro ministro de Bolsonaro, além de direcionar seu discurso na defesa do ESP, deixa visível que a educação brasileira, no sentido amplo, e a docência, no sentido estrito, teriam sido corrompida por "preferências ideológicas" de um partido, reforçando a produção de uma concepção de docência como prática partidária. "(...) a escola é o lugar que abre janela para o conhecimento. Em sua opinião, porém, as escolas não estão desempenhando esse papel desde que o PT assumiu a presidência da República" (RIBEIRO, 2016).

A esse respeito, em entrevista para o BBC Brasil, a professora de história da América Latina e do Caribe, na New York University (EUA) e especializada em Brasil, Barbara Weinstein, traduz a atual conjuntura como um discurso considerado como "acima da ideologia", predominante no governo, mas caracterizado como um subterfúgio para naturalizar suas próprias posições ideológicas. Ademais, a especialista ainda acrescenta que os governos do PT foram claramente ideológicos, contudo "mais flexíveis e centristas" do que as diretrizes do próprio partido antes de assumir a Presidência. Por isso, ela considera que a administração do Bolsonaro tende a ser ainda mais ideológica que os governos anteriores, visto que ele já sinaliza ser pouco aberto para posições divergentes. Nessa senda, a professora ainda argumenta que todo professor parte, em algum grau, de sua própria visão de mundo, quando decide o que vai ensinar e como o fará. Ainda defende que

é o Escola sem Partido e seu esforço para policiar as salas de aula que representam uma ameaça à liberdade acadêmica e à credibilidade das instituições educacionais brasileiras no país e no exterior (...). Há um número inestimável de fatos históricos. A própria seleção de quais fatos apresentar (em sala de aula) é um ato de interpretação" (SCHREIBER, 2018).

Ademais, novas controvérsias surgem dentro do escopo ideológico do próprio presidente eleito, o guru da direita política brasileira, e consultor pessoal do presidente, o filósofo Olavo de Carvalho, em entrevista para o Jornal $O$ Globo, declarou que acredita que o projeto ESP ainda é prematuro. Contudo, elogiou a escolha do cotado futuro ministro da educação, Ricardo Vélez Rodríguez, dizendo que o coIombiano naturalizado "conhece o Brasil mais do que qualquer brasileiro" (O GLOBO, 2018). Em recente fala no congresso nacional, Vélez se manifestou de forma favorável ao que seria a essência ontológica do movimento ESP.

Tenho a impressão que vai sair uma coisa moderada, uma coisa tranquila. 0 que a sociedade não quer é que haja ideologização de gênero ou política para as nossas crianças. Quem educa é o Pai e a Mãe, e a escola tem que respeitar as tradições familiares em que as crianças cresceram (PITOMBO; WILTEMBURG, 2018).

O futuro ministro ainda afirmou que, por mais que muitas famílias brasileiras sejam desestruturadas, não cabe à escola substituir instituição familiar, pois, segundo ele, "amor de pai e mãe ninguém substitui". Portanto, é notável que o governo eleito se articula com um certo grau de coesão interna de discurso na direção de empoderar um modelo educacional que privilegia uma docência articulada à lógica conservadora fundamentada em preceitos morais religiosos, que tenta afastar da sala de aula temas que tratem da diversidade social e de conquistas obtidas pelos movimentos sociais. Pode-se observar isso por meio das premissas presentes no projeto em tramitação na Câmara de Deputados, tal como o banimento dos termos "gênero" e "orientação sexual" de disciplinas e do currículo escolar.

Por esse caráter polêmico, não haveria como o cenário ser homogêneo. Salienta-se que o Supremo Tribunal Federal e os Tribunais Estaduais estão, através de suas decisões, se mostrando como um obstáculo para a implementação de tais propostas. O Jornal Folha de São Paulo mostrou que, em 2018, as cúpulas dos tribunais de ao menos cinco estados (SP, RJ, MG, SE e AM) suspenderam leis municipais 
que proíbem a menção do termo "gênero"(PITOMBO; WILTEMBURG, 2018). Tal quadro se faz relevante, pois a depender do caminho traçado, se mostra como mais uma controvérsia em outro setor social, visto que, segundo o site do jornal El País, além do apoio das bancadas da Bíblia, do boi e da bala, Jair Bolsonaro terá uma bancada dentro do Ministério Público o apoiando, com promotores e procuradores dispostos a defender suas pautas no Congresso, como o ESP (ALESSI, 2018).

Sendo assim, é notável que a temática pode estar caminhando para uma estabilização, quando vista sob um aspecto positivo institucional. Contudo, também há sinalizações para futuras controvérsias, pois, até mesmo partidos políticos, como é o caso do PSB, se posicionam contra o ESP, desenhando um possível cenário de oposição às propostas com o caráter semelhante do movimento em tela (RACY, 2018).

Essa conjuntura ofensiva de enfrentamento que se vislumbra contribui para a produção da docência como prática político-pedagógica, como no exemplo do governo do Maranhão, que editou um decreto por "Escola sem Censura", legitimando sua posição contrária ao ESP. O governador do estado, Flavio Dino, editou decreto que defende a liberdade de expressão dos professores. 0 decreto também determina que filmagens em sala de aula só podem ocorrer, se houver o consentimento docente e dispõe que "todos os professores, estudantes e funcionários são livres para expressar seu pensamento e suas opiniões no ambiente estadual do Maranhão". Segundo o Governador, essa é uma forma de garantir "escolas com liberdade e sem censura" (VALADARES, 2018).

Ademais, essa iniciativa não se revela como isolada. O Deputado Dagoberto Nogueira (PDT) apresentou projeto na Câmara Federal para combater "Escola sem Partido".

A intenção é contrariar este programa (Escola sem Partido), que está sendo defendido pelos aliados do (Jair) Bolsonaro. O nosso projeto quer dar liberdade e acabar com a censura aos nossos professores, que estão sendo penalizados com esta discussão sobre restrições nas salas de aula (ROCHA, 2018).

A esse respeito, ainda se verifica que não apenas em território nacional vemos repercussões sobre a questão. Mais de 150 entidades de 87 países diferentes assinaram uma moção de emergência contra o ESP que tramita, atualmente, no Congresso Nacional. 0 documento que critica a tentativa de lei como censura a professores, ainda dizendo que possui características de "prática persecutória e violadora", que foi aprovado por unanimidade durante a $6^{\text {a }}$ Assembleia Mundial da Campanha Global pela Educação, que ocorreu entre os dias 16 e 18 em Katmandu - Nepal (MORAIS, 2018).

Contudo, ao passo que são manifestadas posições de resistência, é notável que o projeto tenha se proliferado por meio dos apoiadores do novo Governo eleito. Em São Paulo, o Governador eleito João Dória, que apoiou declaradamente Bolsonaro na corrida presidencial, afirmou que "escola é lugar de aprender. Não é lugar de fazer política. Escola sem partido. Essa é a minha posição" (AGÊNCIA ESTADO, 2018).

\section{CONSIDERAÇÕES FINAIS}

A análise das controvérsias acerca do Movimento ESP e sua articulação com a docência na atualidade brasileira permitiu transpassar uma mera observação maniqueísta de disputa de interesses para, de fato, registrar como os mais diversos atores se articulam e traduzem a realidade em meio a tais controvérsias. A temática foi se transmutando em seus diversos mediadores, revelando, dessa maneira, a articulação deles e o surgimento de um cenário heterogêneo em relação à produção da docência.

Pode-se verificar que são múltiplos os elementos que englobam sua fundamentação e legitimação vinculante, desde questões que retomam a construção e legitimação do ofício docente, até às conjun- 
turas políticas disfuncionais que se exteriorizam e se articulam socialmente a partir do ressentimento. É notório que há uma resposta de outros setores sociais ao que parece se configurar como um novo status quo. Diversos são os docentes, juristas e organizações internacionais que fazem uma leitura cautelosa do ESP, que, muitas vezes, se traduz em atitudes energéticas de denúncia e articulações para proteger uma classe que se vê ameaçada no que tange a princípios de liberdade de expressão, que pressupõe uma prática docente articulada à ação político-pedagógica.

Por outro lado, é visível que o argumento sobre uma suposta doutrinação por parte dos professores está ganhando força. Pode-se observar uma potência ainda maior no respectivo argumento, quando ele é disseminado através do senso comum. Por conseguinte, há uma forte articulação para positivar em lei, o que seria uma forma de proteger os interesses da família tradicional brasileira, aproximando o que se entende por educação institucional dos valores conservadores, reforçando as concepções da docência como doutrinadora ou ainda como prática de oportunismo partidário, que devem ser combatidas por uma ação docente articulada a uma lógica conservadora e também dotada de neutralidade. Esse panorama tem impactado até mesmo na atitude de determinados docentes que se veem ameaçados por argumentos que instigam retaliação e denúncias com base em censuras e preconceitos. É o delineamento da docência como prática de acuada e silenciada.

Por fim, deve-se considerar que as eleições presidenciais, em certa medida, fortaleceram as ambições dos atores envolvidos com o ESP, contudo, mesmo levando-se em consideração os circuitos articulados ao presidente eleito, o cenário parece se mostrar ainda altamente volátil, com fluxos que ainda se revelam demasiadamente instáveis. 
Docência na atualidade brasileira:

rastreando controvérsias acerca do movimento Escola Sem Partido

\section{REFERÊNCIAS}

AGÊNCIA ESTADO. Em São Paulo, projeto Escola Sem Partido vira mote de João Doria. Estadão. 2018. Disponível em:https://noticias.r7.com/sao-paulo/em-sao-paulo-projeto-escola-sem-partido-viramote-de-joao-doria-07112018. Acesso em: 7 nov. 2018.

ALESSI, G. 'Bancada' de promotores pró-Bolsonaro se articula em torno de Escola Sem Partido. El País. 2018. Disponível em: https://brasil.elpais.com/brasil/2018/11/20/politica/1542730129_947596. html?\%3Fid_externo_rsoc=FB_BR_CM. Acesso em: 10 set. 2018.

BEDINELLI, T. A educação brasileira no centro de uma guerra ideológica. El País. 2016. Disponível em: https://brasil.elpais.com/brasil/2016/06/22/politica/1466631380_123983.html. Acesso em: 25 jul. 2018.

BETTO, F. "Escola Sem Partido"? In: Ação Educativa Assessoria, Pesquisa e Informação (Org.). A ideologia do movimento Escola Sem Partido: 20 autores desmontam o discurso. São Paulo: Ação Educativa, 2016. p. 65-69.

BOLDRINI, A. Escola Sem Partido avança na Câmara; texto proíbe termo 'gênero'. Folha de São Paulo. 2018. Disponível em: https://www1.folha.uol.com.br/educacao/2018/05/escola-sem-partido-avancana-camara-texto-proibe-uso-do-termo-genero.shtml. Acesso em: 01 ago. 2018.

BRAUN, R. E. Movimento escola sem partido: uma análise crítica sob o âmbito jurídico e social. Conteúdo Jurídico. 2016. Disponível em: http://www.conteudojuridico.com.br/?artigos\&ver=2.56647\&seo=1. Acesso em: 14 set. 2018.

CATELLI JR, R. A criminalização ideológica dos livros didáticos. In: Ação Educativa Assessoria, Pesquisa e Informação (Org.). A ideologia do movimento Escola Sem Partido: 20 autores desmontam o discurso. São Paulo: Ação Educativa, 2016. p. 83-92.

ESP, ESCOLA SEM PARTIDO. Faq. s/d. Disponível em: https://www.programaescolasempartido.org/faq. Acesso em: 10 jun. 2018.

ESP. ESCOLA SEM PARTIDO. PL Municipal. s/d. Disponível em: https://www.programaescolasempartido. org/municipal. Acesso em:10 jun. 2018.

G1. Bolsonaro diz que 'questão ideológica' é grave como a corrupção e precisa ser combatida. G1. 2018. Disponível em: https://g1.globo.com/politica/eleicoes/2018/noticia/2018/10/02/bolsonarodiz-que-a-questao-ideologica-e-grave-como-a-corrupcao-e-precisa-ser-combatida.ghtml. Acesso em: 28 nov. 2018.

GADOTTI, Moacir. Pensamento pedagógico brasileiro. 8. ed. São Paulo: Ática, 2006.

GIROTTO, E. Um ponto na rede: o Escola Sem Partido no contexto da escola do pensamento único. In: Ação Educativa Assessoria, Pesquisa e Informação (Org.). A ideologia do movimento Escola Sem Partido: 20 autores desmontam o discurso. São Paulo: Ação Educativa, 2016. p. 69-76.

LATOUR, B. Reensamblar Lo Social: uma introdución a la teoria del actor-red. Buenos Aires: Manantial, 2008.

LATOUR, B. A Esperança de Pandora: ensaios sobre a realidade dos estudos científicos. Bauru: EDUSC, 2001. 
Julio Cesar de Almeida Nobre I Ivanete da Rosa Silva de Oliveira Marcos Paulo dos Anjos Corrêa de Carvalho / Amanda Braga dos Santos I Matheus Pires Andrade

LATOUR, B. Ciência em ação: como seguir cientistas e engenheiros sociedade afora. São Paulo: Editora UNESP, 2000.

LEMOS, A. A comunicação das coisas: teoria ator-rede e cibercultura. São Paulo: Annablume, 2013.

MORAIS, E. 'Escola Sem Partido' é rejeitada por 150 entidades de 87 países. Blog do Esmael. 2018. Disponível em: https://www.esmaelmorais.com.br/2018/11/escola-sem-partido-e-rejeitada-por-150entidades-de-87-paises/. Acesso em: 10 set. 2018.

MORENO, A. C. Lei não resolve a questão, diz ministro sobre o 'Escola sem Partido'. G1. 2016. Disponível em: https://g1.globo.com/educacao/noticia/lei-nao-resolve-a-questao-diz-ministro-sobre-o-escolasem-partido.ghtml. Acesso em: 22 nov. 2018.

MORENO, A. C.; TENENTE, L.; FAJARDO, V. 'Escola sem Partido': entenda a polêmica em torno do movimento e seus projetos de lei. G1. 2016. Disponível em: https://g1.globo.com/educacao/noticia/ entenda-a-polemica-em-torno-do-escola-sem-partido.ghtml Acesso em: 10 set. 2018.

NOTÍCIAS STF. Suspensa lei alagoana que instituiu o programa Escola Livre. 2017. Disponível em: http://m.stf.gov.br/portal/noticia/verNoticiaDetalhe.asp? idConteudo=338884. Acesso em: 10. Set. 2018.

NÓVOA, A. O processo histórico de profissionalização do professorado: In: Nóvoa A. (org.). Profissão: professor. 2. ed. Porto: Porto Editora, 1995. P. 13-33.

NÓVOA, A. Concepções e práticas da formação contínua de professores: In: Nóvoa A. (org.). Formação contínua de professores: realidade e perspectivas. Portugal: Universidade de Aveiro, 1991.

O GLOBO. "O dia em resumo: Guru de Bolsonaro diz que Escola sem Partido é prematuro". o Globo. 2018. Disponível em:https://oglobo.globo.com/brasil/o-dia-em-resumo-guru-de-bolsonaro-diz-queescola-sem-partido-prematuro-23256946. Acesso em: 10 set. 2018.

PITOMBO, J. WILTEMBURG, L. 'Será uma coisa moderada', diz futuro ministro sobre projeto Escola sem Partido. Folha de São Paulo. 2018. Disponível em: https://www1.folha.uol.com.br/educacao/2018/11/ sera-uma-coisa-moderada-diz-futuro-ministro-sobre-projeto-escola-sem-partido.shtml. Acesso em: 10 set. 2018.

RACY, S. PSB 'fecha questão' nos Estados contra Escola sem Partido. Estadão. 2018. Disponível em:https://cultura.estadao.com.br/blogs/direto-da-fonte/psb-fecha-questao-nos-estados-contraescola-sem-partido/. Acesso em: 10 set. 2018.

RIBEIRO, M.5 opiniões sobre a Escola Sem Partido para você formar a sua. Revista Exame. 2016. Disponível em: https://exame.abril.com.br/brasil/5-opinioes-sobre-a-escola-sem-partido-para-voceformar-a-sua/ Acesso em: 10 jun. 2018.

ROCHA, L. Deputado de MS apresenta projeto para combater "Escola sem Partido". Campo Grande News. 2018. Disponível em: https://www.campograndenews.com.br/politica/deputado-de-ms-apresentaprojeto-para-combater-escola-sem-partido. Acesso em: 10 set. 2018.

SÁ, T. T. A docência no Brasil: história, obstáculos e perspectivas deformação e profissionalização no século XXI. 2016. Disponível em: http://revistas.ufac.br/revista/index.php/tropos/article/download/461/ pdf. Acesso em:10 set. 2018. 
Docência na atualidade brasileira:

rastreando controvérsias acerca do movimento Escola Sem Partido

SCHREIBER, M. É possível governar sem ideologia, como promete Bolsonaro? BBC. 2018. Disponível em: https://www.bbc.com/portuguese/brasil-46307711 Acesso em: 10 set. 2018.

SCHURER, H. A. Lei da Mordaça em São Lourenço do Sul é um atentado à escola pública. Sul21. 2018. Disponível em: https://www.sul21.com.br/opiniaopublica/2018/07/lei-da-mordaca-em-sao-lourencodo-sul-e-um-atentado-a-escola-publica-por-helenir-aguiar-schuerer/ Acesso em: 10 jun. 2018.

TOLEDO, L. F.; CHADE, J. Relatores da ONU classificam 'Escola sem Partido' como 'censura'. Estadão. 2017. Disponível em: https://educacao.estadao.com.br/noticias/geral,relatores-da-onu-denunciamescola-sem-partido-e-classificam-projeto-de-censura,70001737530. Acesso em: 17 set. 2018.

TRAVINCAS, T. Liberdade de ensinar é condição para melhorar nosso debate democrático. São Paulo. EI País. 2018. Disponível em: https://brasil.elpais.com/brasil/ 2018/01/05/politica/1515162915_230395. html. Acesso em: 15 nov. 2018.

VALADARES, J. Contra Escola sem Partido, governo do MA edita decreto por 'escola sem censura'. Folha de São Paulo. 2018. Disponível em:https://www1.folha.uol.com.br/educacao/2018/11/contra-escolasem-partido-governo-do-ma-edita-decreto-por-escola-sem-censura.shtml. Acesso em: 10 set. 2018.

VASCONCELOS, J. S. A escola, o autoritarismo e a emancipação. In: Ação Educativa Assessoria, Pesquisa e Informação (Org.). A ideologia do movimento Escola Sem Partido: 20 autores desmontam o discurso. São Paulo: Ação Educativa, 2016. p. 77-82.

VINCK, D. Sociologie des Sciences. Paris: Armand Colin, 1995. 